\title{
PENGARUH KOMPETENSI, INDEPENDENSI, DAN INTEGRITAS TERHADAP KUALITAS AUDIT DALAM PENGAWASAN KEUANGAN DAERAH (INSPEKTORAT PEMKAB LAMONGAN)
}

(The Effect Of Competency, Independence, And Integrity On Audit Quality In Regional Financial Supervision Inspectorate Of Lamongan Pemkab)

\author{
Sri Yaumi ${ }^{1}$ \\ ${ }^{1}$ Program Studi S2 Akuntansi Universitas Wijaya Kusuma Surabaya, \\ sriyaumistiekhad@gmail.com
}

Info Artikel

Diterima Februai 1, 2021

Direvisi Februari 20, 2021

Dipubikasi Maret 20, 2021

\section{Kata Kunci:}

Independensi, Integritas, Kompetensi, dan Kualitas Audit

\section{Keywords :}

Independence, Integrity, Competence and Audit

Volume 22 No 1 (2021)

\begin{abstract}
Abstrak
Tujuan dari penelitian ini adalah untuk menganalisis pengaruh kompetensi, independensi, dan integritas terhadap kualitas audit dalam pengawasan keuangan daerah. Penelitian ini merupakan penelitian kuantitatif. Sampel penelitian ini adalah aparat di inspektorat yang terlibat langsung (auditor) dalam pengawasan keuangan daerah Pemerintah Kabupaten Lamongan sebanyak 34 orang. Alat analisis yang digunakan adalah SPSS dan data penelitian dinalisis menggunakan regresi linier berganda. Hasil penelitian menunjukkan bahwa kompetensi, independensi, dan integritas berpengaruh terhadap kualitas audit dalam pengawasan keuangan daerah.
\end{abstract}

\section{Abstract}

The study aims to analyze the influence of competence, independence, and integrity on audit quality in 
Quality

\section{PENDAHULUAN}

Tuntutan pelaksanaan akuntabilitas sektor publik terhadap terwujudnya good governance di Indonesia semakin meningkat. Tuntutan ini wajar, karena beberapa penelitian menunjukkan bahwa terjadinya krisis ekonomi di Indonesia ternyata disebabkan oleh buruknya pengelolaan (bad governance) dan buruknya birokrasi. Tiga aspek utama yang mendukung terciptanya kepemerintahan yang baik (good governance) yaitu pengawasan, pengendalian, dan pemeriksaan.

Kebijakan untuk mewujudkan good governance pada sektor publik antara lain meliputi penetapan standar etika dan perilaku aparatur pemerintah, penetapan struktur organisasi dan proses pengorganisasian yang secara jelas mengatur tentang peran dan tanggung jawab serta akuntabilitas organisasi kepada publik, pengaturan sistem pengendalian organisai yang memadai, dan pelaporan eksternal yang disusun berdasarkan sistem akuntansi yang sesuai dengan standar akuntansi pemerintahan. Fenomena yang dapat diamati dalam perkembangan sektor publik saat ini adalah semakin menguatnya tuntutan masyarakat terhadap pelaksanaan akuntabilitas publik oleh organisasi sektor public sehingga memicu timbulnya gejolak yang berakar pada ketidakpuasan dimana tuntutan semakin tinggi diajukan terhadap pertanggung jawaban yang diberikan oleh penyelenggara negara atas kepercayaan yang diamanatkan kepada mereka. Transparansi dan akuntabilitas merupakan syarat adanya efektivitas tata kelola (effective governance) pemerintahan. 
Pengawasan hakekatnya adalah suatu tindakan menilai apakah sesuatu telah berjalan sesuai dengan rencana yang telah ditentukan. Pengawasan merupakan unsur penting dalam proses manajemen pemerintahan, pengawasan memiliki peran yang sangat strategis untuk terwujudnya akuntabilitas publik dalam pemerintahan dan pembangunan melalui suatu kebijakan. Pengawasan juga merupakan salah satu unsur penting dalam rangka menjawab penilaian kinerja atas tuntutan pelaksanaan akuntabilitas organisasi sektor publik terhadap terwujudnya good governance. Pengawasan berfungsi membantu agar sasaran yang ditetapkan organisasi dapat tercapai, serta berperan dalam mendeteksi secara dini terjadinya penyimpangan pelaksanaan, penyalahgunaan wewenang, pemborosan dan kebocoran.

Kualitas hasil pemeriksaan merupakan indikator penilaian terhadap pengawasan yang telah dilakukan oleh aparat pemeriksa. Hasil pemeriksaan yang mempunyai kualitas baik diharapkan mampu memberikan jaminan terhadap tata kelola pemerintahan yang transparansi dan bertanggung jawab. Fungsi pengawasan diwujudkan dalam bentuk kualitas hasil pemeriksaan yang dilakukan oleh aparat pemeriksa untuk memberikan rekomendasi sebagai bahan perbaikan akuntabilitas untuk dapat ditindaklanjuti. Inspektorat sebagai auditor internal pemerintah daerah memiliki peranan yang sangat penting sebagai fungsi pengawasan dalam menciptakan tata kelola pemeritahan yang baik, bebas korupsi, kolusi dan nepotisme (KKN) (Astrawan et al., 2016)

Kualitas hasil pemeriksaan yang baik dapat dicapai apabila seorang pemeriksa memiliki kompetensi, independensi dan integritas yang cukup baik pula. Orang yang berkompeten adalah orang dengan keterampilan mengerjakan pekerjaan dengan mudah, cepat, intuitif dan sangat jarang atau tidak pernah membuat kesalahan. Auditor harus melakukan pelatihan teknis yang cukup agar memiliki keterampilan tersebut. Pencapaian 
dimulai dengan pendidikan formal, yang selanjutnya diperluas melalui pengalaman dan praktek audit. Sikap mental independen sama pentingnya dengan keahlian dibidang praktik akuntansi dan prosedur audit yang harus dimiliki oleh setiap auditor. Auditor tidak hanya berkewajiban mempertahankan sikap mental independen, tetapi juga harus menghindari hal- hal yang dapat mengakibatkan independensinya diragukan masyarakat. Kompetensi, independensi dan integritas yang dimiliki auditor dalam penerapannya akan terkait dengan etika. Akuntan mempunyai kewajiban untuk menjaga standar perilaku etis tertinggi mereka kepada organisasi dimana mereka bernaung, profesi mereka, masyarakat dan diri mereka sendiri dimana akuntan mempunyai tanggungjawab menjadi kompeten dan untuk menjaga integritas dan obyektivitas mereka. Bagi seorang auditor, pengalaman dalam bidang audit berperan penting dalam meningkatkan pengetahuan dan keahlian sehingga kualitas audit akan semakin baik (Wiratama \& Ketut, 2015),

Inspektorat kabupaten / kota merupakan suatu lembaga pengawas dilingkungan pemerintah daerah. Inspektorat Daerah memainkan peran yang sangat penting untuk kemajuan dan keberhasilan pemerintah daerah dan perangkat daerah dalam menyelenggarakan pemerintahan di daerah untuk mencapai tujuan dan sasaran. Inspektorat perlu meningkatkan kinerja yang lebih intensif, agar dalam pelaksanaan tugasnya lebih optimal dan maksimal. Kinerja dari Inspektorat Daerah sangat penting, oleh karena dengan adanya kinerja maka tingkat pencapaian hasil akan terlihat melalui tugas dan wewenang yang diberikan dapat dilaksanakan secara maksimal (Febriansyah et al., 2013).

Kebijakan untuk mewujudkan good governance pada sektor publik antara lain meliputi penetapan standar etika dan perilaku aparatur pemerintah, penetapan struktur organisasi dan proses pengorganisasian yang secara jelas mengatur tentang peran dan tanggung jawab serta akuntabilitas organisasi kepada publik, pengaturan sistem Volume 22 No 1 (2021) 
pengendalian organisasi yang memadai, dan pelaporan eksternal yang disusun berdasarkan sistem akuntansi yang sesuai dengan standar akuntansi pemerintahan (Febriansyah et al., 2013).

Beberapa peneliti telah melakukan penelitian mengenai hubungan kompetensi, independensi dan integritas terhadap kualitas audit. Hasil studi (Perdany, 2013) menyatakan bahwa kompetensi berpengaruh signifIkan terhadap kualitas audit. Sedangkan hasil studi (Turangan et al., 2016) serta (Syarifudin, 2014) menyatakan bahwa kompetensi tidak berpengaruh terhadap kualitas audit. Hasil studi (Perdany, 2013) menyatakan bahwa independensi tidak berpengaruh terhadap kualitas audit. Berbeda dengan hasil studi Faizah (2016) dan (Irwan, 2019) menyatakan bahwa independensi berpengaruh terhadap kualitas audit. Hasil studi (Rohman \& Parasayu, 2014) menyatakan bahwa integritas berpengaruh terhadap kualitas audit.

Penelitian ini penting dilakukan agar dapat diketahui faktor-faktor yang memengaruhi kualitas audit dan dapat meningkatkan kualitas audit yang dihasilkannya. Tidak mudah menjaga independensi dan integritas auditor. Kompetensi yang melekat pada auditor bukan jaminan bahwa auditor dapat meningkatkan kualitas hasil pemeriksaannya. Penelitian ini penting untuk menilai sejauh mana auditor pemerintah dapat konsisten menjaga kualitas jasa audit yang diberikannya. Selain itu, beberapa hail penelitian yang tidak konsisten menarik untuk dilakukannya penelitian ulang. Oleh sebab itu, tujuam dari penelitian ini adalah untuk menganalisis pengaruh kompetensi, independensi dan integritas terhadap kualitas (Turangan et al., 2016)audit dalam pengawasan keuangan daerah. 


\section{JURNA \\ ANALISIS, PREDIKSI, DAN INFORMASI}

\section{METODE PENELITIAN}

Populasi yang dipergunakan dalam penelitian ini adalah APIP (Aparat Pengawas Internal Pemerintah) yang bekerja di Inspektorat Kabupaten Lamongan sejumlah 34 orang. Sampel dalam penelitian ini adalah pegawai yang terlibat audit di inspektorat dalam pengawasan keuangan daerah Pemerintah Kabupaten Lamongan sebanyak 34 (tiga puluh empat).

Teknik pengambilan sampel dalam penelitiaan ini adalah teknik total sampling. Total Sampling adalah teknik pengambilan sampel dimana jumlah sampel sama dengan populasi (Sugiyono, 2013). Alasan mengambil total sampling karena menurut jumlah populasi yang kurang dari 100 seluruh populasi dijadikan sampel penelitian semuanya (Sugiyono, 2013).

\section{Metode Analisis Data}

Peneliti menggunakan SPPS sebagai alat analisisnya. Langkah awal, peneliti akan melakukan uji validitas dan reliabilitas. Uji validitas dilakukan untuk menjelaskan apakah instrument yang digunakan untuk memperoleh data dalam penelitian dapat digunakan ataupun tidak (Sugiyono, 2013:267). Uji realibilitas dilakukan untuk mengetahui seberapa jauh hasil pengukuran tetap konsisten apabila dilakukan pengukuran dua kali atau lebih terhadap gejala yang sama dengan menggunakan alat pengukur sama (Santi, 2019)

Sebelum data penelitian dianalisis menggunakan analisis regresi Linier Berganda, peneliti terlebih dahulu melakukan uji asumsi klasik yang terdiri atas uji normalitas, uji multikoliniearitas dan uji heterokedasitas. Persamaan penelitian dapat dirumuskan sebagai berikut:

$$
\mathrm{Y}=\mathrm{a}+\mathrm{b} 1 \mathrm{x} 1+\mathrm{b} 2 \times 2+\mathrm{b} 3 \times 3+\mathrm{e}
$$




$\begin{array}{ll}\text { a } & : \text { Konstantan } \\ \text { b1, b2, b3 } & : \text { Koefisien Regresi } \\ \text { X1 } & \text { : Kompetensi } \\ \text { X2 } & : \text { Independensi } \\ \text { X3 } & : \text { Integritas } \\ \text { Y } & : \text { Kualitas Audit } \\ \text { e } & : \text { Eror. }\end{array}$

\section{HASIL DAN PEMBAHASAN}

Dari hasil uji validitas dan reliabilitas, 29 instrumen dikatakan valid dan reliable. Dua puluh sembilan pernyataan yang terdapat pada kompetensi, independensi, integritas, dan kualitas audit memiliki nilai Cronbach's Alpha masing-masing 0.786, 0.859, 0.904, dan 0.879. Data tersebut menyatakan bahwa nilai pada Cronbach's Alpha $>0.60$. Dapat disumpulkan bahwa peryataan yang terdapat pada variable kinerja sudah valid dan reliabel dan dapat memenuhi syarat pada uji validitas dan reliabilitas.

Uji normalitas dengan menggunakan analisis grafik dilakukan dengan melihat normal probability plot yang membandingkan distribusi kumulatif dari distribusi normal. Dengan melihat tampilan grafik normal plot dapat terlihat bahwa data atau titik-titik menyebar disekitar garis diagonal dan mengikuti arah garis diagonal, maka dapat dinyatakan bahwa model regresi memenuhi asumsi normalitas. Hasil uji normalitas dengan menggunakan analisis grafik dapat dilihat pada Gambar 4.2 di bawah ini. 


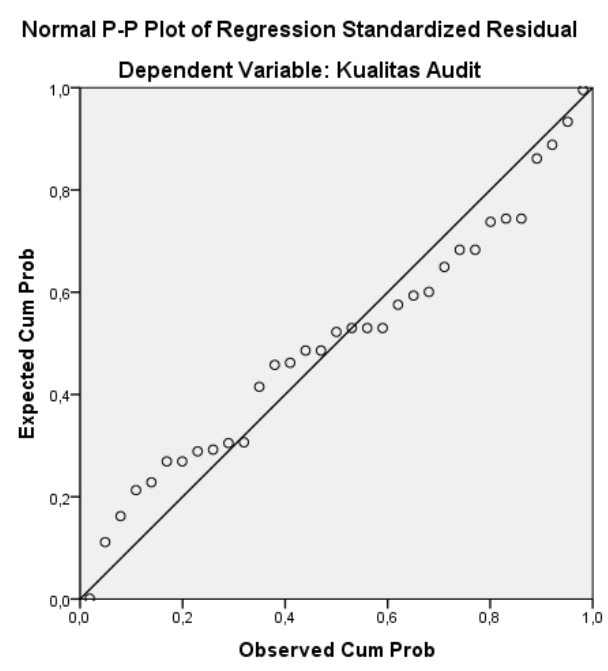

Gambar 1. Hasil uji normalitas

Sumber : Hasil penelitian, 2020 (data diolah)

Untuk uji multikolinearitas pada penelitian ini adalah dengan melihat nilai Tolerance dan Variance Inflation Factor (VIF) variabel kompetensi, independensi, dan integritas. Nilai Tolerance untuk masing-masing variabel independen yang diuji adalah $0.609,0.887,0.554$ yang artinya nilai Tolerance kurang dari 0,10 yang berarti tidak ada korelasi antar variabel independen. Sedangkan nilai VIF masing-masing variabel independen $1.643,1.128$, dan 1.806 juga menunjukkan hal yang sama tidak ada satu variabel independen yang memiliki nilai VIF lebih dari 10. Jadi dapat disimpulkan bahwa tidak ada multikolonieritas antar variabel independen dalam model regresi pada penelitian ini.

Dari Gambar dibawah ini terlihat bahwa titik-titik menyebar secara acak serta tersebar baik di atas maupun di bawah angka 0 pada sumbu Y. Hal ini dapat disimpulkan bahwa model regresi linier berganda dalam penelitian ini tidak mengandung adanya heteroskedastisitas. 


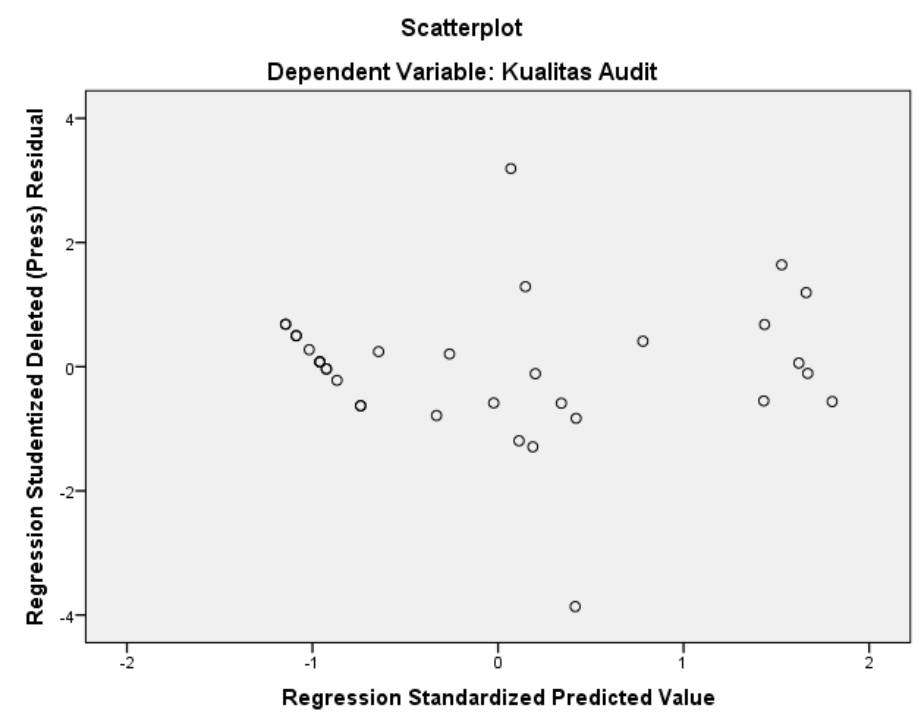

Gambar 1. Hasil uji Heteroskesdasitas

Sumber : Hasil penelitian, 2020 (data diolah)

Hasil analisis uji autokorelasi melalui SPSS pada Durbin-Watson menunjukan bahwa nilai Durbin-Watson sebesar 1.738 Nilai tersebut mendekati 2, dengan demikian dapat disimpulkan bahwa tidak terjadi autokorelasi diantara data pengamatan.

Hasil pengujian regresi linier berganda pada penelitian ini dapat dilihat sebagai berikut: 


\section{JURNAL

Tabel 1 Coefficients

\begin{tabular}{|c|c|c|c|c|c|c|c|}
\hline \multirow[b]{2}{*}{ Model } & \multicolumn{2}{|c|}{$\begin{array}{c}\text { Unstandardized } \\
\text { Coefficients }\end{array}$} & \multirow{2}{*}{$\begin{array}{c}\begin{array}{c}\text { Standardized } \\
\text { Coefficients }\end{array} \\
\text { Beta }\end{array}$} & \multirow[b]{2}{*}{$\mathrm{t}$} & \multirow[b]{2}{*}{ Sig. } & \multicolumn{2}{|c|}{$\begin{array}{c}\text { Collinearity } \\
\text { Statistics }\end{array}$} \\
\hline & B & $\begin{array}{l}\text { Std. } \\
\text { Error }\end{array}$ & & & & Tolerance & VIF \\
\hline $1 \quad$ (Constant) & 6,935 & 2,262 & & 3,066 &, 005 & & \\
\hline $\begin{array}{l}\text { Kompetensi } \\
\text { Auditor }\end{array}$ & ,597 &, 104 & ,397 & 5,759 &, 000 & ,609 & 1,643 \\
\hline Independensi & ,251 & ,096 & , 149 & 2,613 & ,014 & ,887 & 1,128 \\
\hline Integritas & ,610 & ,064 & ,689 & 9,521 &, 000 & ,554 & 1,806 \\
\hline
\end{tabular}

a. Dependent Variable: Kualitas Audit

Sumber : Hasil penelitian, 2020 (data diolah)

Berdasarkan Tabel 4.14 dapat dituliskan persamaan regresi linier berganda sebagai berikut :

$$
\mathrm{Y}=6.935+0.597 \mathrm{X} 1+0.251 \mathrm{X} 2+0.610 \mathrm{X} 3+\mathrm{e}
$$

Dari tabel diatas diperoleh nilai thitung dari setiap variabel independen dalam penelitian ini. Nilai thitung dari setiap variabel independen akan dibandingkan dengan nilai ttable dengan menggunakan tingkat kepercayaan (confidence interval) $95 \%$ atau $\alpha=$ 0,05 maka diperoleh nilai ttabel 2,04.

Hasil pengujian hipotesis pertama secara parsial menunjukkan bahwa variabel kompetensi (X1) memiliki nilai thitung (5.759) > nilai ttabel $(2,04)$, maka keputusannya adalah menerima Ha dan $\mathrm{H} 0$ ditolak. Hal ini berarti variabel kompetensi berpengaruh signifikan terhadap kualitas audit inspektorat dalam pengawasan keuangan daerah kabupaten Lamongan. 
Hasil pengujian hipotesis ini sejalan dengan pendapat De Angelo bahwa kemungkinan (probability) dimana auditor akan menemukan salah saji tergantung pada kualitas pemahaman auditor (kompetensi). Hasil penelitian ini sejalan pula dengan hasil penelitian yang dilakukan oleh Harhinto (2004) bahwa keahlian yang diproksikan dalam intensitas pengalaman dan tingkat pengetahuan auditor berhubungan positif terhadap kualitas audit. Senada dengan hasil studi dari Perdany \& Suranta (2013), Triarin \& Latrini (2016), Dewi \& Nurfadila (2018) serta Santi (2019).

Hasil tersebut dapat dipahami bahwa untuk meningkatkan kualitas audit, seorang auditor sangat bergantung pada tingkat kompetensinya. Jika auditor memiliki kompetensi yang baik maka auditor akan dengan mudah melakukan tugas-tugas auditnya dan sebaliknya jika rendah maka dalam melaksanakan tugasnya, auditor akan mendapatkan kesulitan-kesulitan sehingga kualitas audit yang dihasilkan akan rendah pula.

Hasil pengujian hipotesis kedua secara parsial menunjukkan bahwa variabel independensi (X2) memiliki nilai thitung (2.613) > nilai ttabel $(2,04)$, maka keputusannya adalah menerima Ha dan HO ditolak. Hal ini berarti variabel Independensi berpengaruh signifikan terhadap kualitas audit inspektorat dalam pengawasan keuangan daerah kabupaten Lamongan.

Hasil penelitian ini sama dengan hasil penelitian Faizah (2016) dan Santi (2019) menyatakan bahwa independensi berpengaruh terhadap kualitas audit. Hasil penelitian Turangan et al. (2016) juga menyatakan bahwa independensi berpengaruh positif terhadap kualitas audit.

Hasil pengujian hipotesis ketiga secara parsial menunjukkan bahwa variabel Integritas (X3) memiliki nilai thitung (9.521) > nilai ttabel (2,04), maka keputusannya adalah menerima Ha dan $\mathrm{H} 0$ ditolak. Hal ini berarti variabel Integritas berpengaruh 


\section{JURNA \\ ANALISIS, PREDIKSI, DAN INFORMASI}

signifikan terhadap kualitas audit inspektorat dalam pengawasan keuangan daerah kabupaten Lamongan.

Hasil penelitian ini sesuai dengan hasil penelitian Rohman \& Parasayu (2014) dan Santi (2019). Hal tersebut menunjukkan bahwa dengan integritas yang tinggi, maka auditor dapat meningkatkan kualitas audit yang dihasilkannya. Dengan mempertahankan integritas, seorang auditor akan bertindak jujur, tegas dan tanpa pretensi. Tanpa sikap integritas ini maka laporan audit yang dihasilkan tidak dapat memenuhi kriteria yang diharapkan dan dapat menjadi bias. Integritas mengharuskan seorang anggota untuk, antara lain, bersikap jujur dan berterus terang tanpa harus mengorbankan rahasia penerima jasa. Pelayanan dan kepercayaan publik tidak boleh dikalahkan oleh keuntungan pribadi. Integritas dapat menerima kesalahan yang tidak disengaja dan perbedaan pendapat yang jujur, tetapi tidak dapat menerima kecurangan atau peniadaan prinsip.

\section{KESIMPULAN DAN SARAN}

\section{Kesimpulan}

Kompetensi berpengaruh terhadap kualitas audit dalam pengawasan keuangan daerah. Hasil penelitian ini selaras dengan beberapa penelitian sebelumnya. Akan tetapi bertentangan dengan Turangan et al. (2016) serta Syarifudin (2014) menyatakan bahwa kompetensi tidak berpengaruh terhadap kualitas audit. Independensi berpengaruh terhadap kualitas audit dalam pengawasan keuangan daerah. Hasil penelitian ini selaras dengan beberapa penelitian sebelumnya. Akan tetapi bertentangan dengan hasil studi Perdany \& Suranta (2013) menyatakan bahwa independensi tidak berpengaruh terhadap kualitas audit. Integritas berpengaruh terhadap kualitas audit dalam pengawasan keuangan daerah. Integritas berpengaruh terhadap kualitas audit dalam pengawasan keuangan daerah sesuai dengan hasil penelitian Rohman \& Parasayu (2014) dan Santi 
(2019) juga menyatakan bahwa integritas berpengaruh signifikan terhadap kualitas audit.

Keterbatasan dari penelitian ini adalah (1) objek penelitian hanya pada Inspektorat Pemerintah Kabupaten Lamongan, (2) pengumpulan data hanya menggunakan kuesioner, (3) variabel independen yang diteliti berpengaruh terhadap variabel kualitas audit sebesar $91,6 \%$, berarti bahwa ada pengaruh sebesar 8,4\% dari variabel-variabel lain di luar model. Saran dari penelitian ini adalah (1) memperluas objek penelitian pada aparat inspektorat kabupaten/kota se-Jawa Timur, sehingga hasilnya dapat digeneralisasi, (2) penelitian ini sebaiknya menggunakan metode mix method dalam pengumpulan datanya agar hasil penelitian jauh lebih dalam, (3) penelitian selanjutnya disarankan untuk menambahkan variabel-variabel lain yang belum termasuk dalam model regresi pada penelitian ini.

\section{UCAPAN TERIMA KASIH}

Dalam penyusunan naskah publikasi ilmiah yang sederhana ini, penulis mendapat bantuan dari berbagai pihak, untuk itu penulis mengucapkan terima kasih kepada: Kolaborator dan rekan-rekan Dosen di Universitas Wijaya Kusuma yang telah membantu dan membimbing untuk penelitian ini. Akhirnya ucapan terima kasih disampaikan kepada semua pihak yang tidak dapat disebutkan satu persatu.

\section{DAFTAR PUSTAKA}

Asosiasi Auditor Intern Pemerintah Indonesia, (AAIPI), A. A. I. P. I. (2014). Standar Audit Internal Pemerintah Indonesia.

Astrawan, I. K. Y., Mimba, N. P. S. H., \& Dwirandra, A. A. N. . (2016). Etika memoderasi pengaruh kompetensi, pengalaman dan independensi pada kualitas hasil 


\section{JURNA \\ ANALISIS, PREDIKSI, DAN INFORMASI}

pemeriksaan inspektorat. E-Jurnal Akuntansi Unversitas Udayana, 5(6), 18411862. https://ojs.unud.ac.id/index.php/EEB/article/view/14986/14773

Ayuningtyas, harvita yulian, \& Pamudji, S. (2012). Pengaruh Pengalaman Kerja, Independensi, Obyektifitas, Integritas Dan Kompetensi Terhadap Kualitas Hasil Audit. Universitas Diponegoro Semarang, 2(1), 1-10. https://ejournal3.undip.ac.id/index.php/accounting/article/view/581/583

BPKP, P. (2005). Kode Etik dan Standar Audit (Keempat).

Badriyah, N., \& Muhtarom, A. (2020, January). Configuration of Employment Training to Improving Work Competencies Toward Competitiveness. In 17th International Symposium on Management (INSYMA 2020) (pp. 303-306). Atlantis Press.

Dewi, R. K., \& Nurfadila, S. (2018). Pengaruh Kompetensi Auditor, Profesionalisme, Dan Sistem Pengendalian Internal Terhadap Kualitas Audit. CESJ: Center Of Economic Students

DJ, Y. R. (2016). PENGARUH TINGKAT SUKU BUNGA TERHADAP SIMPANAN MUDHARABAH PADA BANK UMUM SYARIAH DI INDONESIA. JPIM (Jurnal Penelitian Ilmu Manajemen), 1(2), 9-Halaman.

DJ, Y. R. (2017). ANALISIS PENGARUH EXPERIENTIAL MARKETING TERHADAP LOYALITAS PELANGGAN (STUDY KASUS DI CV. LAMONGAN SPORTS CENTER). JPIM (Jurnal Penelitian Ilmu Manajemen), 2(3), 8-Halaman.KECAMATAN TURI LAMONGAN. Media 


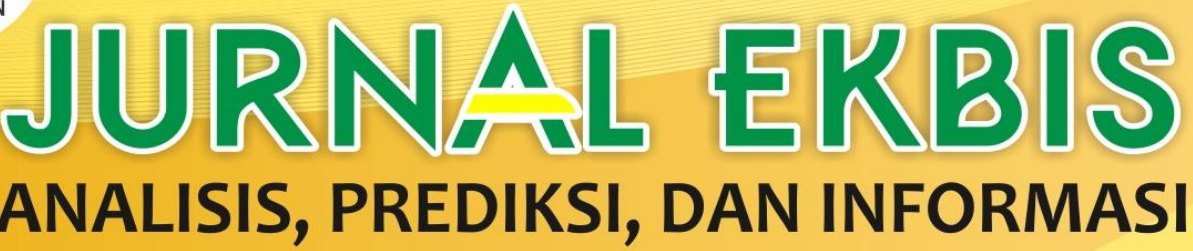

Mahardhika, 17(1), 46-53.

DJ, Y. R., \& Titin, T. (2020, October). THE EFFECT OF E-RECRUITMENT AND SPIRIT AT WORK ON EMPLOYEE ACHIEVEMENT AT PT X IN SURABAYA. In 1st International Conference of Business and Social Sciences.

Efendy, M. T. (2010). Pengaruh Kompetensi, Independensi, dan Motivasi Terhadap Kualitas Audit Aparat Inspektorat Dalam Pengawasan Keuangan Daerah. Jurnal Ilmiah Akuntansi. https://doi.org/10.1017/CBO9781107415324.004

Efendi, Y., Mahrus, M., \& Wijayanto, D. (2020). Analisis Model Altman Z-Score Dalam Memprediksi Kebangkrutan Pada Perusahaan Perbankan Swasta Nasional Devisa Yang Go Public Di Bursa Efek Indonesia (Periode 2015-2017. Jurnal Sains Sosio Humaniora, 4(1), 259-263.

Efendi, Y., Mauladi, K. F., Rahmi, C. A., \& Afifah, D. N. (2020). Pelatihan Dan Bantuan Dalam Program Pemberdayaan Ekonomi Pada Masa Pandemi Di Desa Tiwet Kecamatan Kalitengah Kabupaten Lamongan. Jurnal Karya Abdi Masyarakat, 4(3), 711-714.

Faizah, A. R. (2016). Pengaruh Financial Distress, Diclosure, Perkara Pengadilan dan Opini Audit Tahun Sebelumnya Terhadap Opini Audit Going Concern. JRA FEB Unisma, 6(4), 120-135. http://riset.unisma.ac.id/index.php/jra/article/view/350/391 


\section{JURNA A \\ ANALISIS, PREDIKSI, DAN INFORMASI}

Febriansyah, E., Rasuli, M., \& Hardi, H. (2013). PENGARUH KEAHLIAN, INDEPENDENSI, KECERMATAN PROFESIONAL, DENGAN ETIKA SEBAGAI VARIABEL MODERASI TERHADAP KUALITAS AUDITOR PADA INSPEKTORAT PROVINSI BENGKULU. SOROT, 8(1), 1-34. https://doi.org/10.31258/sorot.8.1.2346

Hasiholan, L. B., \& DJ, Y. R. (2019). Strategi Positioning Dalam Upaya Membangun Brand. Jurnal Penelitian IPTEKS, 4(2), 229-240.

Irawan, M. R. N. (2020). PENGARUH KUALITAS PRODUK, HARGA DAN PROMOSI TERHADAP MINAT BELI KONSUMEN PADA PT. SATRIA NUSANTARA JAYA. Jurnal Ekonika: Jurnal Ekonomi Universitas Kadiri, 5(2), 140-156.

Irwan, D. (2019). PENGARUH KOMPETENSI, INDEPENDENSI, DAN ETIKA TERHADAP KEMAMPUAN MENDETEKSI KECURANGAN DALAM PENYUSUNAN AUDIT DIINTERAKSI OLEH PENGALAMAN AUDITOR (Studi pada Auditor BPKP Perwakilan Provinsi Sulawesi Tenggara).

Irawan, M. R. N., Mauladi, K. F., Herlianto, A. M., \& Nurhayati, L. (2020). Analisis Pola Pembiayaan Sistem Kredit Pemilikan Rumah Dan Pola Pembiayaan Tunai Terhadap Peningkatan Rentabilitas Pada PT. Karya Usaha Mandiri Pratama Lamongan. Jurnal Sains Sosio Humaniora, 4(2), 942-949.

Mulyadi. (2008). Auditing (1st ed.). Salemba Empat. 
Najiah, E. F., \& DJ, Y. R. (2018). PENGARUH PROGRAM DANA BERGULIR OLEH UPK DAN TENAGA KERJA TERHADAP PENINGKATAN PENDAPATAN KUWA DI DESA BAMBANG

Nasriana, Basri, H., \& Abdullah, S. (2015). Pengaruh Kompetensi, Independensi,Obyektivitas Kecermatan Profesional dan Pengalaman Audit Terhadap Kualitas Audit (Studi pada Pemeriksa Inspektorat Kabupaten/Kota di Aceh). Magister Akuntansi Pascasarjana Universitas Syiah Kuala.

Perdany. (2013). PENGARUH KOMPETENSI DAN INDEPENDENSI AUDITOR TERHADAP KUALITAS AUDIT INVESTIGATIF PADA KANTOR PERWAKILAN BPK-RI YOGYAKARTA. Journal of Chemical Information and Modeling.

Perdany, A., \& Suranta, S. (2013). Pengaruh Kompetensi dan Independensi Auditor Terhadap Kualitas Audit Investigatif pada Kantor Perwakilan BPK-RI YOGYAKARTA. Jurnal Akuntansi Dan Bisnis, 3(1). http://eprints.ums.ac.id/43288/4/NASKAH PUBLIKASI.pdf

Rohman, A., \& Parasayu, A. (2014). ANALISIS FAKTOR-FAKTOR YANG MEMPENGARUHI KUALITAS HASIL AUDIT INTERNAL (Studi Persepsi Aparat Intern Pemerintah Kota Surakarta dan Kabupaten Boyolali). Diponegoro Journal of Accounting. 


\section{JURNA

Santi, E. I. (2019). Pengaruh Kompetensi, Independensi, Motivasi, Akuntabilitas dan Integritas Terhadap Kualitas Audit Pada Inspektorat Kabupaten Lamongan, Kabupaten Bojonegoro dan Kabupaten Tuban [Universitas Wijaya Kusuma Surabaya]. http://blog.umy.ac.id/ervin/files/2012/06/aspsia13.pdf

Sugiyono. (2013). Metode Penelitian Kuantitatif, Kualitatif dan R\&D. CV. Alfa Beta.

Sukriyah, I., Akram, \& Inapty, B. A. (2009). Pengaruh Pengalaman Kerja, Independensi, Obyektifitas, Integritas dan Kompetensi Terhadap Kualitas Hasil Pemeriksaan Oleh: Pengaruh Pengalaman Kerja, Independensi, Obyektifitas, Integritas Dan Kompetensi Terhadap Kualitas Hasil Pemeriksaan.

Syarifudin, A. (2014). Pengaruh Kompetensi SDM dan Peran Audit Intern terhadap Kualitas Laporan Keuangan Pemerintah Daerah dengan Variabel Intervening Sistem Pengendalian Internal Pemerintah (studi empiris pada Pemkab Kebumen). Fokus Bisnis: Media Pengkajian Manajemen Dan Akuntansi, 13(2). https://doi.org/10.32639/fokusbisnis.v13i2.22

Triarin, D. A. W., \& Latrini, M. Y. (2016). Pengaruh Kompetensi, Skeptisme Profesional, Motivasi, Dan Disiplin Terhadap Kualitas Audit Kantor Inspektorat Kabupaten/Kota Di Bali. E-Jurnal Akuntansi Universitas Udayana, 14(2), 1092-1119. https://103.29.196.112/index.php/Akuntansi/article/view/14911/12604

Turangan, F. M., Saerang, D. P. . E., \& Sondakh, J. J. (2016). PENGARUH SKEPTISISME PROFESIONAL，KOMPETENSI， DAN INDEPENDENSI AUDITOR TERHADAP KUALITAS PEMERIKSAAN DALAM 


\section{PENGAWASAN KEUANGAN DAERAH DENGAN KEPATUHAN PADA KODE ETIK SEBAGAI VARIABEL MODERATING. JURNAL RISET AKUNTANSI DAN AUDITING “GOODWILL,” 7(2), 71-88. https://doi.org/10.35800/jjs.v7i2.13553}

Wiratama, W. J., \& Ketut, B. (2015). Pengaruh Independensi, Pengalaman Kerja, Due Professional Care Dan Akuntabilitas Terhadap Kualitas Audit. E-Jurnal Akuntansi Universitas Udayana, 10, 91-106. 